American Journal of Applied Science 2 (9): 1321-1324, 2005

ISSN 1546-9236

(C) Science Publication, 2005

\title{
Induction of Micronuclei in Mice Lymphocytes Exposed to Microwave and Toluene
}

\author{
S.B. Mortazavi, A. Safari, A. Khavanin, A. Kazemnejad, \\ ${ }^{1}$ S.M. Moazzeni and Abbas Rezaee \\ ${ }^{1}$ Departement of Immunology Medical, \\ Faculty Tarbiat Modarres University, Tehran, Iran \\ Department of Occupational and Environmental Heals Medical, \\ Faculty Tarbiat Modarres University, Tehran, Iran
}

\begin{abstract}
Increasing applications of microwave radiation are of great concern with regard to public health. Several studies have been conducted detect effects of microwave exposure genetic material leading to negative or questionable results. The Micronucleus (MN) assay which is proved to be a useful method for detection of radiation exposure-induced cytogenetic damage was used in the present study to investigate the genotoxic effect of microwave and toluene alone and in combination in Balb/c lymphocytes. The electromagnetic field with two frequencies $(980,950 \mathrm{MHz}, 200 \mathrm{KHz} \mathrm{Mod}), 5 \mathrm{w}$ and $500 \mathrm{ppm}$ Toluene applied for two weeks. Microwave irradiation had no significant effect on the frequency of micronucleus induced, but exposure of animals to toluene alone and in combination with microwave have significantly increased the induced micronucleus $(\mathrm{p}<0.05)$. Indeed combination exposure of microwave and toluene showed higher rates of micronucleus in comparison with toluene alone. This study indicated that microwave radiation cannot induce any significant cytogenetic effects but, in combination with toluene could show synergistic effect.
\end{abstract}

Key words: Microwave, toluene, lymphocytes, micronucleus, mice

\section{INTRODUCTION}

Applications of microwave have been increased in recent years due to radars and police communication systems ${ }^{[1]}$, high power satellite and TV transmitters, mobile phones, microwave ovens and medical devices ${ }^{[2]}$. The biological effects of this type of exposure on living organisms have been studied by different investigations ${ }^{[3,4]}$. The absorption of electromagnetic energy can cause biological effects in tissues. The Specific Absorption Rate (SAR) has been introduced for the assessment of absorbed energy from electromagnetic fields with biological systems. SAR measurement requires complicated technical procedures ${ }^{[5]}$. Several biological effects of microwave exposure such as effects on eyes, gonads and circulatory system can be thermal effects. It has shown that endogenous biological electrical activities of can be categorized as nonthermal effects of microwave exposure which occurs in low powers ${ }^{[6]}$. Occupational and non occupational exposure to low power microwave and its biological effects have increased in recent years.

Toluene as a chemical material have various industrial applications such as Benzene production, inks, adhesives and leather industry ${ }^{[7]}$ Occupational exposure of 1,278000 American workers to toluene during 1981-1982 has been reported by $\mathrm{NIOSH}^{[8]}$. Vehicles and their fueling procedures are the main sources of toluene environmental pollution and therefore transportation employees are exposed to toluene occupationally ${ }^{[9]}$ Toluene introduced as an alternative for Benzene but there are controversies about its harmful biological effects of toluene on lymphocytes of workers is reported ${ }^{[12,13]}$. By talking to accounting the probable harmful biological effects of microwave exposure and toluene alone and together, we planned this study to investigate the synergistic effects of two these agents.

\section{MATERIALS AND METHODS}

Animals: We used the micronucleus assay for quantification of cytotoxic effects of microwave and toluence on balbc lymphocytes ${ }^{[14]}$. The micronucleus assay was carried by lymphocyte cells of male bulb/c mice aged 2 months weighting $18-25 \mathrm{~g}$. Five equal populations ${ }^{[6]}$ experimental groups were used in various conditions. There was a control group for each experimental group.

Corresponding Author: $\quad$ S.B. Mortazavi, Department of occupational and Environmental Heals medical faculty tarbiat modarres university, Tehran, Iran 
Am. J. Applied Sci., 2 (9): 1321-1324, 2005

Table 1: Micronucleus in lymphocytes after microwave and toluene exposure

\begin{tabular}{lllllll}
\hline Groups & power $[\mathrm{w}]$ & frequency $[\mathrm{MHz}]$ & $\begin{array}{l}\text { Exposure time } \\
{[\text { week] }}\end{array}$ & Modulation & $\begin{array}{l}\text { Toluene } \\
\text { MHz }\end{array}$ & $\begin{array}{l}\text { MN*/1000 } \\
\text { ppm [mean } \pm \text { SD] }\end{array}$ \\
\hline 1 & 5 & 950 & 2 & - & - & $14.16 \pm 1.47$ \\
control & - & - & - & - & - & $11.66 \pm 1.03$ \\
2 & 5 & -290 & - & - & - & $13.83 \pm 1.47$ \\
control & - & - & 2 & - & - & $12 \pm 1.26$ \\
3 & 5 & - & - & - & - & $13.5 \pm 1.37$ \\
control & - & - & - & - & - & $12 \pm 0.89$ \\
4 & - & - & - & - & - & $17.66 \pm 3.66^{* *}$ \\
control & - & - & - & - & 500 & $11.33 \pm 1.21$ \\
5 & 5 & - & - & - & - & $25.5 \pm 4.63^{* *}$ \\
control & - & - & - & & $11.83 \pm 1.16$ \\
\hline
\end{tabular}

*Frequency of Micro Nucleus (MN) expressed as number of micronucleus in binuleated cells (BN) on 1000 $* * \mathrm{P}<0.05$

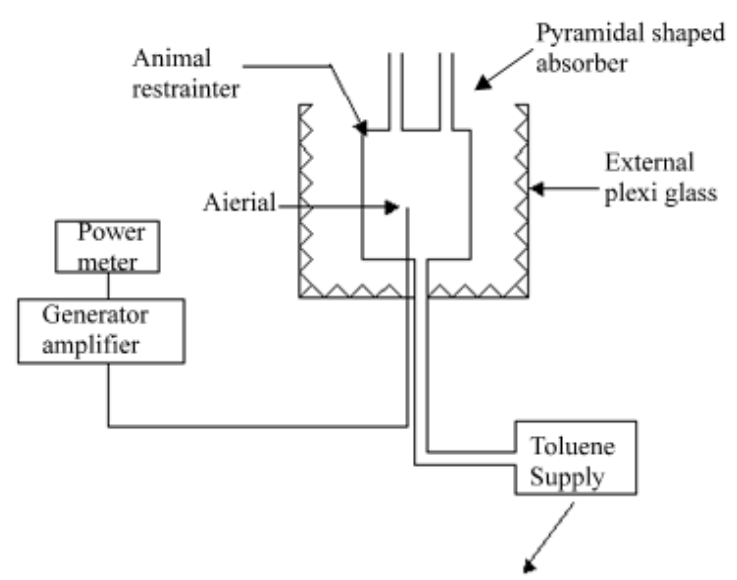

Fig. 1: Toluene supply and microwave irradiation setup

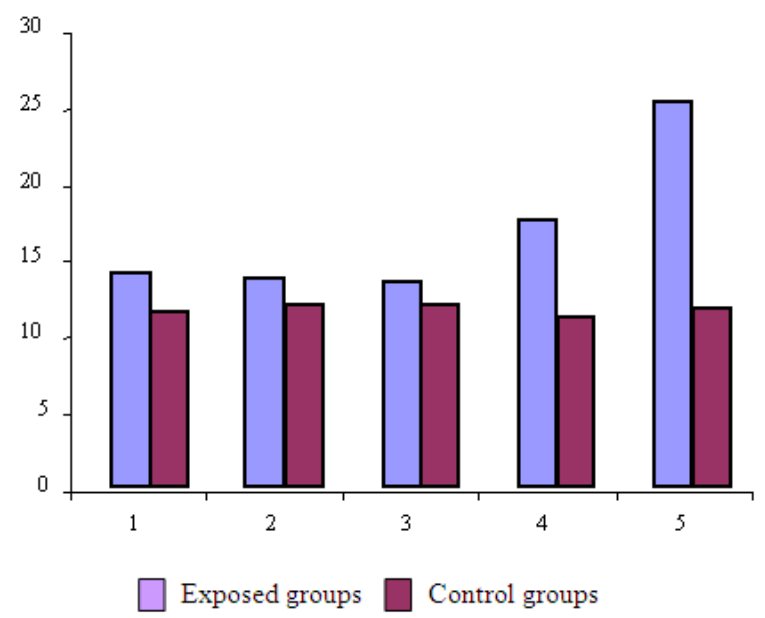

Fig. 2: Frequency of micronucleus in control groups

Microwave irradiation and toluene exposure: The experimental setup for microwave irradiation and toluene exposure was shown in Fig. 1.

The generator, amplifier $(800-950 \mathrm{MHz}, 3-5 \mathrm{w})$ and Arial designed and constructed in the electrical engineering faculty of Khaje Nasiredine toosi university and the animal restrainer Plexiglass cylinder $[30 \mathrm{~cm}$ diameter and $30 \mathrm{~cm}$ height] was mounted inside the chamber $(110 \times 110 \times 110 \mathrm{~cm})$ with absorber material. The aerial and the inlet of toluene supply was mounted on the floor of the restrainer. Five groups of equal population 6 , male balb/c mice were used in this study. All groups were irradiated by microwave and or exposed to toluene for two weeks and 8 hours per day in various condition. Group $1(950 \mathrm{MHz}, 5 \mathrm{w} \mathrm{RF}] 2[890$ $\mathrm{MHz}$, 5w RF) $3(950 \mathrm{MHz}$, 5w, with $200 \mathrm{KHz}$ modulation), 4(no RF, $500 \mathrm{ppm}$ toluene) and 5 (950 $\mathrm{MHz}, 5 \mathrm{w}$ RF and 500 ppm toluene).

Micronuclei in cultured lymphocytes: All animals were sacrificed and their splenic cells were isolated by injection of RPMI 1640 medium (Gibco) to their spleen followed by grinding true cell mesh and focal density gradient centrifugation $(700 \mathrm{~g}, 15 \mathrm{mim}), 200 \mu 1$ of each cell suspension was cultured at $37{ }^{\circ} \mathrm{C}$ and $5 \% \mathrm{CO}_{2}$ in RPMI medium containing $10 \%$ fetal serum (FCS, Gibco) and 1.5\% Phytohemagglotinin (PHA, Gibco). After 17.5 hours of incubation cytochalosin- B (Cyt- B, sigma, $6 \mu / \mathrm{ml}$ final concentration) was added to cell cultures. The cells were harvested after another 24 hours of incubation and laid slide using cytospin. The frequency of binucleate cells after methanol fixation and Gisma staining using light microscope.

\section{RESULTS}

Frequency of induced micronucleus observed in 10 groups including the control and exposed groups and corresponding statically analysis for each group are given in Table 1.

Mean frequency of induced micronucleus in 5 groups were 14.16, 13.83, 13.5, 17.66 and 25.5 respectively which with their corresponding control groups are shown in Fig. 2.

ANOVA analysis showed that the differences between groups of 4 and 5 and their controls were statistically significant, but no significant difference 
was observed in the other three groups (groups 1,2 and $3)$. The difference between groups 5 and 6 was significant as well $(\mathrm{p}<0.5)$.

\section{DISCUSSION}

Microwave telecommunication systems as an electromagnetic field used in our environment leading raised the natural electromagnetic noise by a factor of about $10^{12}$.Exposure of large groups of the population to this type of electromagnetic field and the probable biological effects on living organisms have revived considerable research attention ${ }^{[3,15,16]}$. Biological effects at a cellular and molecular level such as DNA damage, chromosomal aberration probable genotoxic effects. Microwave telecommunication systems have been reported by several investigations ${ }^{[17-20]}$. Toluene as a chemical volatile agent has been used widely in various industries and as an air Pollutant could exposure population. The cytogenetic effects of toluene have been reported in recent years ${ }^{[12,13]}$.

We considered the genotoxic effects of microwave and toluene alone and together by micronucleus assay. MN formation is correlated with the loss of either chromosome fragments or whole chromosomes. Due to their relatively small size, the microwave-induced MN here observed are likely hypothesized to arise via a clastogenic $^{[2]}$. The present work indicates that exposure to non-ionizing radiation in the range of microwave with toluene is able to cause, increase of lymphocytes MN frequency. This finding adds further evidence in favor of the use of cytogenetic assays as a dosimetry biomarker in epidemiological studies of workers occupationally exposed to a combination of non ionizing radiation and chemical agents. The microwave exposure of $890,950 \mathrm{MHz}$ and power of $5 \mathrm{w}$ has no significant effect on the frequency of micronucleus observed. This result is in agreement with an investigation that used $935.2 \mathrm{MHz}$ and $4.5 \mathrm{w}$ power density ${ }^{[21]}$ and also agrees with other study which used $\mathrm{RF}$ frequencies of 380,900 and $1800 \mathrm{MHz}$ with Amplitude modulation of $0.73-3.1 \mathrm{MHz}$ on incidence of Sister Chromatid Exchange (SCE) of human lymphocytes ${ }^{[22]}$. We also showed that exposure to 500 ppm toluene increased induced frequency of $\mathrm{MN}$ that agrees with investigation that reported occupational exposure to $40 \mathrm{ppm}$ toluene ${ }^{[23,12,24]}$ simultaneous exposure of microwave and toluene has higher micronucleus induction in compression with microwave and toluene alone which is in agreement with study that investigated the simultaneous effects of microwave and mitomycin on human blood cells in vitro ${ }^{[2]}$ it must be considered that really there are many chemical agents and an electromagnetic field which is genotoxic in our living and working environment, hence so, the synergistic effects of these chemical and physical agents can be considered as future investigations.

\section{REFFERENCES}

1. Vera Garaj- vrhovac, 1999, Micronucleus assay and lymphocyte mitotic activity in risk assessment of occupational exposure to microwave radiation. Chemosphere, 39: 2601- 2312.

2. Laura, Z.M. and P. Mrio, 2000, Induction of micronucleus in human lymphocytes exposed in vitro to microwave radiation. Mutation Research, 472: 51-58.

3. Maryama, M. Salesman and R.D. Broadwell, 1991, Blood brine barrier alternation after microwaveinduced hyperthermia is purely a thermal effect temperature and power measurements. Surg. Neurol., 35: 177-182.

4. Garaj-Vrhovac, S. Vojdic, A. Fucis and D. Kubelka, 1996, Effect of $415 \mathrm{MHz}$ frequency on human lymphocyte genome. In: Proceeding of IRPAg Congress, 3: 604-606.

5. Michaelson, 1991, Biological effects of radiofrequency radiation: concepts and criteria. HealthPhyss., 61: 3-14.

6. Frochlich, H., 1980, The biological effects microwave and related questions. Adv Electronic Electron Phys., 53: 85-152.

7. IRAC, 1981, Monographs on the evaluation of carcinogenic risks to human, wood, leather and some associated industries, 22: 222.

8. NIOSH, 1983, National, occupational exposure survey 1981- 1983, Cincinnati, OH.

9. Pitarque, M., A. Creus, R. Marcos, J. A. Hughes and D. Anders, 1999, Examination of various biomarkers measuring genotoxic endpoints from Barcelona airport personnel. Mutation research, 440: 185-207.

10. Pitarque, M., A. Vaglenov, M. Nosko, A. Hirvonen, H. Norppa, A. Creus and R. Marcos, 1999, Evaluation of DNA damage by the Comet assay in shoe workers exposed to toluene and other organic solvents. Mutation Research, 441: 115127.

11. Mcgregor, D., 1994. The genetic toxicology of toluene. Mutation Research, 317: 213- 228.

12. Funes-Cravioto, F.B. kolmodin-Hedman, J. Lindsten, M. Nordenskjold, Z. Gayon, B. Lambert, E. Norberg, R. Olin and A. Swensson, 1977, chromosome aberration and SCEs in workers in chemical laboratory and a rotoprinting factory and in woman children of woman laboratory workers. Lancet ii, pp: 233-235. 
13. Bauchinger, M., E. Schmid, J. Dresp, J. kolinGerresheim, R. Hauf and E. Suhr, 1982, Chromosome changes in lymphocytes after occupational exposure to toluene. Mutation Research, 102: 439- 445.

14. Fenech, 1985, The cytokinsis- block micronucleus technique: to detailed description of the method and its application to genotocicity studies in human Population. Mutation Research, 285: 35-44.

15. Brusich, R. Alberini, D. Mcree, D. Peterson, G. Williams, P. Hanawalt and J. Preson, 1998, Genetoxicity of radiofrequency radiation. Environmental Mutagen, 32: 1-16.

16. Grandolfo, M, 1986, Laprotezions dacampi electromagetic nonionization. ISPRA courses, Ispra.

17. Linj, C, 1971, Health aspects of radio and microwave exposure. Am. Ind. Hyg. Assoc., 32: 338-45.

18. Goldsmith, J.R., 1995, Epidemiological Evidence of Radiofrequency Radiation [Microwave] Effects on Health in Military, Broadcasting and occupational studies Int. . J. occup. Environ.., 1: 47-57.

19. Szmigielski, 1994, Retrospective analysis of cancer morbidity in Polish military personnel exposed during service to Radiofrequency and microwave radiation. In abstracts conference of effect of RFEM radiation on organisms, Skrunda, Latvia.
20. Garaj-Vrhovac, V., A. fucic and B. PEVALEKkozlina, 1993, The rate of elimination of chromosomal aberration after accidental exposure to microwave radiation. Bioelectrochemistry and Bioelectromagnetics, 30: 319-325.

21. Maes, A., M. Collier, U. Van Gorp, S. Vandonick and L. Vershaeve, Cytogenetic effects of 935.2$\mathrm{MHz}$ [GSM] microwaves alone and in combination with mitromycin C. Mutation Research, 393: 151156.

22. Antonopoulos, H. Eisenbrandt and G. Obe, 1999, Effect of high frequency electromagnetic fields on human lymphocytes in vitro. Mt. Res., 395: 209214.

23. Nise, G., B. Hogsted, I. Bratt, S. Skerfving, 1991, Cytogentic effects in rotogravure Printers exposed to toluene and benzene. Mutation Research, 261: 217-223.

24. Mcgregor, D., 1994, The genetic toxicology of toluene. Mutation research, 317: 213-228. 